\title{
ANTROPÓNIMOS MUSULMANES EN LOS ACTUALES PARTIDOS JUDICIALES DE FALSET Y GANDESA
}

Para realizar un inventario exhaustivo de los actuales apellidos españoles que fueron llevados por los mudéjares o moriscos, sería necesario recurrir a las listas del censo electoral o a las fichas del documento nacional de identidad $y$, tras su despoje sistemático, habría que proceder a ordenarlos alfabéticamente y estudiar, a base de los fogatges y nóminas medievales, ${ }^{1}$ cuáles fueron los utilizados. Así tendríamos los puntos inicial y final de una cadena que habria de irse formando, a partir de sus extremos, mediante el estudio de los eslabones interrnedios. Parece inútil decir que un trabajo realizado de acuerdo con esos supuestos es materialmente imposible, puesto que el llevarlo a la práctica requeriría un gran número de años y un equipo nutrido de colaboradores. Que sepamo: se inició -y no se continúa - hace ya tiempo para los apellidos de las Baleares (Estudio General Luliano) y para los de Cataluña (Oficina Románica de Linguística y Literatura. Biblioteca Balmes. Barcelona).

En estas circunstancias no queda más remedio que el de allegar materiales que se ajusten, aunque sea cle modo remoto, a la primera parte del método expuesto más arriba prescindiendo —obvias son las dificultades que presentade la justificación de los eslabones intermedios. Se trata de descubrir en los repertorios antroponímicos más en uso, nombres de etimología árabe (el análisis de las nóminas demuestra que la mayoría de moriscos o mudéjares llevaban apellidos de este tipo), o aquellos otros que, sin ser de raigambre árabe, nos consta que fueron llevados pos los moriscos de la zona estudiada.

Los repertorios onomásticos que están al alcance son, principalmente: 1) El Anuario Telefónico (citado en lo sucesivo como Anuario; se ha utilizado la edición de 1960-61), que tiene la ventaja de agrupar los apellidos en grandes listas alfabéticas por municipios y 2) el Anuario General de España ${ }^{2}$ (en Io sncesivo abreviado AGE; se ha utilizado la edición de 1960), que agrupa

1. Los principales trabajos sobre el tera - en lo que afecta a la región levantina - son: F. Matav.

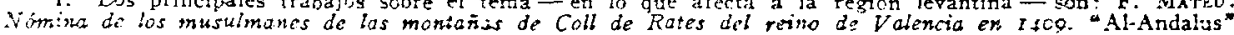

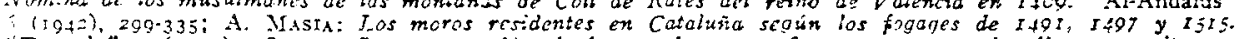
"Trmuda" 3 (1953), $282-200$. La comparacico de los nombres que finuran en estas dos listas permite ver al distinto grado de evolución de los dialectcs árabes bablados en ambas zonas. En los rombres publicados wor F. Mateu están mucho mas próximos al árabe literal que los de A. Masiá. Estudios conexos con estos

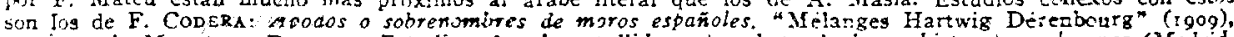
323-334; A. Martsta PATARES. Estudis sobe los apellidos y mombres de lugar hispanomusmimones (Madrid,

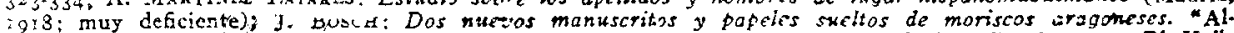
Andalus" 22 (1957), 403-470. (véase la bibliografia citada en este ultimo artículo); J. Verset: El Valle del Ebro como nexo entre Oriente y Ocridente. BRABI-B 23 (1050), 249.286 : M. GRat: Cuntribución al esiudio del estado cultural del Valle de? Ebro en ol siglo $X I$ y principics del XII. BRABLB 27 (1957-5?". $2: 7-272$. Los dos últimos trabajos contienen repertorios, bastante extensos, de los antroponimos de dichil región bajo el dominio musulmán.

?. También conocido con el nombre de Bailly-Baillière-Riera. 
al elemento oficial, comerciantes, industriales, etc., por provincias y, dentro de éstas, por partidos judiciales y municipios. La mayor riqueza del $A G E$ salta a la vista si se tiene en cuenta, sobre todo en los pueblos, que el número de teléfonos es muy escaso en comparación con el de alcaldes, maestros, comerciantes, industriales, etc., que viven sin tener en su domicilio dicho aparato. En cambio, presenta el inconveniente de disponer los apellidos por profesiones y cargos, lo cual hace su manejo muy lento e impide realizar estudios masivos. En resumen: Para una primera aproximación es preferible utilizar el Anuario y para precisar los resultados obtenidos con éste, conviene manejar el AGE.

Una lectura del Anuario permite ver ${ }^{3}$ que la provincia de Tarragona tiene un $1,4 \%$ de habitantes cuyo apellido paterno es de etimología árabe. Cabe pensar que, dentro ya de la Provincia, la distribución de los mismos no sea homogénea y que debe alcanzar una mayor densidad en los lugares que ocuparon, durante más tiempo, los moriscos, es decir, en la zona ribereña del Ebro. A un lado y otro de ese río se extienden hoy los partidos judiciales de Falset y Gandesa (prescindimos intencionadamente del de Tortosa), a cuyo análisis se procede, a continuación, reduciéndolo a los municipios en los que nos consta, directa o indirectamente, que hubo morerías (por esta razón se han añadido los de Tivenys y Benifallet) y algunos otros de su inmediata vecindad

Los principales apellidos anotados son:

ADELL: El Diccionari català-valencià-balear de Alcover y Moll (DCVB) lo deriva de Atellus. Dada la distribución del apellido se trata, probablemente, de una formación haplológica derivada de Atadill.

Alcoverro: Procede de al-qubbayr, ala cupulita, con vocal final de apo. yo o (como en fulano).

Axrrós: Cf. J. Vernet: Antropónimos árabes conservados en apellidos del Levante español. «Oriens . 16 (1963), 154-161.

ARGrLAGA: Citado en Els llinatges... En el siglo xv era apellido morisco.

Cf. A. Masià : Los moros...

Arrízz: Procede de al-raiss, ajefen.

Atadill: Probablemente procede de la forma verbal substantivizada (como Taglib) $t a^{c} d i l$ con artículo. aJuston, nequitativon. Variante Altadrls.

AYET: Els llinatges... lo deriva, dubitativamente, del latín allietum, acampo de ajosn. Parece más probable que tenga una etimología árabe. En primèr lugar figura ya en el siglo xv como nombre propio de los moriscos de la zona (cf. A. Masià: Los moros...) bajo las formas Eye, Aliet. Puede proceder de "ayyād, "recaderon, o de hayya, "culebran (recuérdese la expresión "es una culebran), cuyas evoluciones fonéticas no parecen ofrecer dificultades (cf. el topónimo Beniaya). Se conserva, como nombre propio, en Marruecos.

Azuara: Procede de al-zuwāga, nombre de una tribu bereber y de un poblado africano. El paso $g>r$ para un oído no árabe, que confunde con facilidad las guturales, es probable. (Cf., a título de ejemplo, la especial transcripción $r$ de la letra gayn poŕ bastantes arabistas franceses del siglo pasado.)

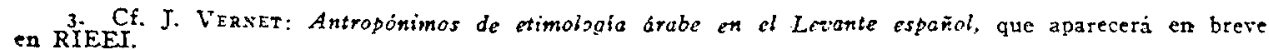

4. Los datos del DCVB, muy interesantes y nutridos, se han tenido en cuenta muy relativamente por
registrar, de modo casi exclusivo, la localizacion registrar, de modo casi exclusivo, la localización geografica de los apellidos sin alvdir a su numero. Un 
Binavís: DCVB lo deriva de bearnés. Posible etimología árabe de $(y \bar{a})$ abi-l-dänis. Ei paso $d>r$ es frecuente (recuérdese asíndrian; cf. A. Steiger: Contribución a la fonética del hispanoúrabe $y$ de los arabismos en el iberorrománico y en el siciliario, Madrid, 1932, p. 133). „Padre del sucio, del impuro» (¿aludirí a una familia islamizada tardíamente?). Más dificultades presenta la etimología a partir de barānis, amiserables (cf. Dozy: Suplement I, 79).

BISET: Procede de $(y \bar{a}) a b \bar{\imath} Z a y d$, antropónimo árabe.

Btrata: Aparece varias veces con la forma Buret en el fogatge de 1497 (cf. A. Masià : Los moros...). Procede de Abu Ridà, antropónimo árabe.

CARm: Procede del antropónimo árabe Karim.

$\mathrm{Cm}$ : Procede del nombre árabe sayyid, aseñor

ECHE: Procede de 'ily, «cristianon, arenegadon, aislamizado (cf. Dozy: Supplement... II, 159). Como nombre propio existe aún hoy en día en Siria. FANECA: 'Atestiguado ya, como apellido morisco, con la forma Feniga, en el fogatge de 1497 (cf. A. Masià : Los moros...). Procede de fäniga, "niñera", o de haniqa, airasciblen.

GEBELL: Els llinatges...; Huctúa entre la etimología italiana y la árabe. Dada el área de distribución, creemos que se trata del arabismo yabalí, amontaraz”.

Małń: Procede de Muhammad/Aamede/Mamed. (Cf. A. Steiger: Contribución..., p. 261.)

MARGALEF: Cf. J. Vernet: Antropónimos árabes...

Margalés: Procede de marya, apradon. El paso de $y$ a $g$ romance se realiza con cierta frecuencia. La $l$ constituye un fonema colectivizante; cf. marjal, barrizal, robledal...

RADtiA: Procede de Ridwān, antropónimo árabe de uso frecuente.

Rort́s: Procede de raffãs, strilladorn.

Rorív: Procede de răhin, rehén", adelgados. Para el paso de $\bar{a}>0$, cf. A. Steiger: Contribución..., p. 311. Por lo demás, esta evolución, de tipo cananaico, es frecuente en los dialectos derivados del árabe.

Rufat: Procede de ruhät, smolineros» (Arrufat, alos molinerosn).

Saladí: Puede proceder de sāhib al-diya, adeudor del precio de la sangren, ahomicidan.

Tunú : La etimología árabe, a partir de taruru, aricon, no es excesivamente clara. Sería tal vez preferible la bereber de turugí (aún hoy así en marroquí moderno), aperteneciente a la tribu de los targan (una de las que formaron parte de la confederación almorávid).

Vechava: Els llinatges... lo deriva del latín Vettiana, que, a su vez, procedería de Vettius. Podría ser, sin embargo, un derivado de $(y \bar{a})$ abi Zayyān (nombre bereber). El paso bi>be (vg. Beceite) - ue - ve, es inmediato. Zayyoun, con monoptongación (frecuente en los dialectos árabes) y paragoge de $a$ y unión con el elemento antericr, daría Veciana.

Vivalxa: Cf. J. Vernet: Antropónimos árabes.:

Los nombres recogidos se distribuyen de la siguiente forma: ( $a$ = nombre del municipio; tras éste, la indicación (m) indica que tuvo morería; $b=$ número de habitarites; $c=$ número de apellidos citados por el 
AGE; $d=$ número de apellidos citados por el Anuario; $e=$ número de apellidos musulmanes; $f=$ porcontaje de apellidos musulmanes respecto del total citado por el $\mathrm{AGE} ; \mathrm{g}=$ porcentaje de moriscos calculado por J. Iglésies en Distribució comarcal de la població catalana a la primera meitat del segle XVI, Barcelona, 1957.)

\begin{tabular}{lrrrrrc}
\multicolumn{1}{c}{$a$} & \multicolumn{1}{c}{$b$} & \multicolumn{1}{c}{$c$} & \multicolumn{1}{c}{$d$} & \multicolumn{1}{c}{$e$} & $f$ & $g$ \\
Falset & 2338 & 217 & 73 & 3 & 1,38 & \\
Capsanes & 723 & 66 & 11 & 2 & 3,03 & \\
García (m) & 963 & 68 & 6 & 2 & 2,91 & 31,29 \\
Guiamets & 397 & 34 & 6 & 2 & 5,38 & \\
Masroig & 861 & 42 & 11 & 3 & 7,14 & \\
Mora la Nueva & 2784 & 182 & 46 & 3 & 1,64 & \\
Tivisa (m) & 2558 & 118 & 13 & 8 & 6,77 & 28,29 \\
Vinebre (m) & 700 & 60 & 9 & 3 & 5,00 & 55,26 \\
Gandesa & 3094 & 242 & 82 & 7 & 2,89 & \\
Ascó (m) & 1885 & 112 & 10 & 6 & 5,60 & 82,31 \\
Benisanet (m) & 1689 & 216 & 21 & 13 & 6,00 & \\
Flix & 4272 & 264 & 52 & 4 & 1,51 & 29.52 \\
Miravet (m) & 999 & 102 & 4 & 2 & 1,96 & 96,92 \\
Mora (m) & 3367 & 393 & 133 & 6 & 1,52 & 28,41 \\
Ribarroja (m) & 1920 & 102 & 10 & 4 & 3,96 & \\
Tivenys (m) & 1446 & 83 & 8 & 2 & 2,40 & 46,15 \\
Benifallet & 1479 & 93 & 11 & 6 & 6,45 & 49,10
\end{tabular}

Del cuadro se deduce: 1) Que el número de antropónimos moriscos y de origen árabe representa un $3,834 \%$, es decir, más del doble que el número $(1,4$ g) correspondiente a la provincia. 2) La media $(4,010 \tilde{c})$ de los municipios que tuvieron morería es ligeramente superior a la de los que no la tuvieron $(3,659 \%)$. 3) El bajo promedio alcanzado por Flix, a pesar de lo importante que fue su morería, tiene su razón de ser en la fuerte inmigración recibida en el transcurso de los últimos cien años como consecuencia de su desarrollo industrial. 4) La localización geográfica de esos apellidos, y en especial los porcentajes obtenidos para Tivisa $(6,7 ;)$ y el, a primera vista aberrante, de Masroig $(7,14, g)$ pueden interpretarse teniendo en cuenta la endogamia, tan frecuente entre la gente de campo, y la falta de corrientes migratorias. La lectura de las listas de censo electoral de Tivisa me ha confirmado en la idea de que los tantos por ciento de apellidos de etimologia árabe obtenidos son ligeramente inferiores a la realidad.

Todo lo dicho parece dar razón a la sospecha de J. Iglésies (Distribució comarcal...) respecto a la instalación geogrífica de los colonos moriscos : aSembla tenir tendència a separar-se de les dues grans localitats - Tortosa i Lleida- d'aquesta zona i a agrupar-se en localitats petites, on devia poder-se moure amb major llibertat.n

Universidad de Barcelona.

J. Vernet 